\title{
LA RENOVACIÓN DE LOS GRUPOS BURGUESES EN GALICIA EN LA SEGUNDA MITAD DEL SIGLO XVIII
}

\author{
por' \\ PEGERTO SAAVEDRA
}

En diversas publicaciones recientes se viene insistiendo en que en la Galicia de la segunda mitad del XVIII y primer tercio del XIX las actividades no específicamente agrarias, en particular la fabricación y venta de lienzos, tuvieron una importancia fundamental, cosa que por lo demás, ya advirtieran contemporáneos como Campomanes, Cónsul Jove o Lucas Labrada. La desindustrialización que se produce en el curso del XIX, con la liquidación primero del textil rural y después de la siderurgia tradicional y de los curtidos, borró casi por completo la memoria histórica - ahora recuperada - de una época en la que Galicia exportaba algo más que fuerza de trabajo y ganado vacuno ${ }^{1}$.

Sabemos, por otra parte, gracias a diversos trabajos — debidos los más tempranos a la pluma de A. Meijide Pardo-, que desde 1760 arribaron a Galicia numerosos mercaderes foráneos, que llegaron a manejar en algu-

\footnotetext{
${ }^{1}$ Vid., en especial, J. Carmona, El atraso industrial de Galicia. Auge y liquidación de las manufacturas textiles (1750-1900), Barcelona, 1990; J. Carmona y J. García Lombardero, "De fábrica dispersa a pariente de aldea: la cuestión industrial en los orígenes de la Galicia contemporánea", en E. Fernández de Pinedo y J.L. Hernández Marco, La industrialización del Norte de España, Barcelona, 1988; P. Saavedra, "Desarrollo y crisis de la industria textil en Galicia: la lencería, 1600-1840", Cuadernos de Investigación Histórica 7 (1982).
}

"CUADERNOS DE ESTUdIOS GALLEGOS", Tomo XLI, Fascículo 106, Santiago 1993-94. 
nos casos un notable volumen de negocios ${ }^{2}$. Debemos pues interrogarnos qué relación hay entre el desarrollo industrial y el avecindamiento en las poblaciones urbanas gallegas de una "nueva burguesía"; en qué medida este grupo social es responsable, primero, de la expansión y, luego, del fracaso de unas actividades que, en el momento de su mayor desarrollo, prometían sacudir los cimientos de una sociedad formada básicamente por campesinos y rentistas. A esta finalidad, y a manera de síntesis, están consagradas las páginas que siguen, deudoras de las investigaciones que se irán relacionando.

\section{I.- LA SITUACIÓN A MEDIADOS DEL XVIII: UNA BURGUE- SÍA COMERCIAL IRRELEVANTE}

A través de los libros personales y respuestas generales del catastro de Ensenada conocemos al menos el número y las utilidades fiscales de las personas que, a mediados del siglo XVIII, se dedicaban al comercio en los principales núcleos urbanos. Y lo primero que ha de resaltarse es la debilidad, en el plano económico y social, de la burguesía, poco numerosa y de cortos caudales. Esta constatación tampoco supone sorpresa alguna, habida cuenta de la escasa importancia de la población urbana en la Galicia de la época. En efecto, la ciudad más populosa, Compostela, rondaba los 4.500 vecinos y 16.000 hbs.; seguíanle Coruña con 2.000 vecinos, Pontevedra con 1.315, Betanzos y Tui con 900, mientras Lugo y Ourense no llegaban a los 800 y Montoñedo ni siquiera a los 600. En rigor, no más del 5 por cien de la población merecía entonces el calificativo de "urbana"3.

\footnotetext{
${ }^{2}$ Cfr. A. Meijide Pardo, "Hombres de negocios en la Galicia deciochesca: Jerónimo de Hijosa", Revista del Instituto José Cornide de Estudios Coruñeses, 3 (1967); "Un capitán de industria en la Galicia del Antiguo Régimen", Anuario de Historia Económica y Social, I (1968); Economía maritima de la Galicia cantábrica en el siglo XVIII, Valladolid, 1971, y también la contribución del mismo autor a la obra colectiva Vigo en su Historia, Vigo, 1980. Aparte están aún sus numerosos trabajos dedicados a los negociantes catalanes. L. Alonso Álvarez, Comercio colonial y crisis del Antiguo Régimen en Galicia (1778-1818), Xunta de Galicia, 1986; X.R. Barreiro Fernández, "La burguesía compostelana: la familia 'De Andrés García' (1760-1815)", en R. Villares (coord.), La ciudad y el mundo urbano en la Historia de Galicia, Santiago, 1988, e Historia contemporánea de Galicia, Coruña, 1984, tomo IV.

${ }^{3} \mathrm{Cfr}$. A. Eiras Roel, "Una primera aproximación a la estructura demográfica de Galicia en el censo de 1787", en R. Villares (coord.), La ciudad y el mundo urbano..., op.cit.
} 
No deja de ser significativo el advertir que entre los años finales del siglo XVI y la época de realización del catastro de Ensenada tuvo lugar un proceso de "desurbanización". Hacia 1590 un 10 por cien aproximado de los habitantes de Galicia vivían en núcleos de 300 o más vecinos, pero en el decurso del XVII y primera mitad del XVIII, mientras crecía fuertemente la problación rural - que en todo el Reino debió aumentar en torno a un 75 por cien-, ciertas villas y la ciudad de Ourense perdían vecinos. Así, Pontevedra aparece en los Expedientes de Hacienda de 1588 con 1.500 fuegos, un 12 por cien más que en 1752; Ourense pierde, entre 1597 y 1752 , de una cuarta a una quinta parte de su vecindario; Verín nota un descenso de dos tercios, y Noia ve descender el número de bautizados de una media anual de 110 en 1540-53 a 55 en 1750-59... Al contrario, Santiago, Coruña, Lugo y Mondoñedo registran un considerable incremento de sus efectivos demográficos, en consonancia con la propia coyuntura agraria - a excepción de la de las comarcas de monocultivo vitícola-y, en el caso coruñés, debido a los efectos que para la ciudad tuvo el gozar de los grandes beneficios del "favor real"4.

En definitiva, desde finales del XVI algunos núcleos pesqueros (Pontevedra, Noia) y otros situados en comarcas vitícolas (Ourense, Verín) perdieron población, de acuerdo con la coyuntura por la que atravesaron esas actividades. La estructura profesional de Pontevedra en 1752 poco tiene que ver con la que presentaba siglo y medio antes: en las diversas averiguaciones para la renovación de los encabezamientos de alcabalas aparece como un activo núcleo de "mareantes" agrupados en el gremio "do Corpo Santo", capaces de hacer frente al 50 por cien del precio del encabezamiento - que supera al de cualquier otra villa o ciudad de Galicia-y de levantar la bella iglesia de Santa María la Grande; cuando se efectúa el catastro de Ensenada la villa del Lérez se caracteriza por ser un centro de artesanos y burócratas: el 10 por cien de sus 1.315 vecinos dependen de la administración real, 101 son sastres, 68 zapateros, 74 carpinteros y canteros, 31 toneleros y otros tantos herreros; en cambio sólo se censan 140 pescadores y navegantes, además de algunas viudas de hom-

${ }^{4}$ Los datos de finales del XVI proceden los Expedientes de Hacienda del Arch. General de Simancas, legs. 97, 118, 135, 144 y 86; los de 1752 de los libros personales del catastro de Ensenada de los respectivos núcleos urbanos.

"CUADERNOS DE ESTUDIOS GALLEGOS", Tomo XLI, Fascículo 106, Santiago 1993-94. 
bres que desempeñaran estas profesiones ${ }^{5}$. A la sazón era el trabajo femenino, en particular en el textil, el que daba cierto dinamismo a la que otrora fuera la primera población urbana de Galicia: el Catastro enumera 18 calceteras, 40 costureras, 21 hilanderas, 4 lenceras y nada menos que 320 palilleras. Si observamos la distribución de alcabalas en las décadas de 1580 y 1780 tendremos un argumento más para reafirmarnos en los cambios en la dedicación profesional de los vecinos:

Distribución de las alcabalas de Pontevedra en 1584 y 1780. En \%

\begin{tabular}{|c|c|c|c|}
\hline \multicolumn{2}{|c|}{ Encabezamiento de 1584} & \multicolumn{2}{|c|}{ Id., de 1780} \\
\hline Ramo & $\%$ & Ramo & $\%$ \\
\hline Pescado, alfolí, media diezma & 47,5 & Vino por menor & 39 \\
\hline Vino & 20 & Carnicería & 11,3 \\
\hline Salvajina & 10,8 & Aceite y jabón & 8 \\
\hline Madera & 6,6 & Tejidos de lana & 7,5 \\
\hline Plaza y pan & 4,1 & Tiendas & 8,3 \\
\hline Paños & 3,8 & Mercado & 6,8 \\
\hline Carnicería & 2,3 & Puertas & 5,2 \\
\hline Cueros y zapatería & 2,1 & Pescadería & 3,6 \\
\hline Fierro & 1,8 & Zapateros & 3,1 \\
\hline Bestias y negros & 0,3 & Sobresaliente & 2,9 \\
\hline Cestería & 0,7 & Géneros ultramarinos & 2,3 \\
\hline & & Trajineros & 1,4 \\
\hline & & Herreros & 0,6 \\
\hline TOTAL & 100 & & 100 \\
\hline
\end{tabular}

Fuente: AGS, EdH, leg. 144, para 1584, y DGR, 1ª R., leg. 2159, para 1780.

Entre una y otra fecha los pescadores han casi desaparecido a la hora de distribuir el encabezamiento entre los diferentes miembros; el gremio de toneleros ("madera"), vinculado a la exportación de vino, también parece haber perdido buena parte de su importancia. En 1780 las alcabalas

\footnotetext{
${ }^{5}$ C. Fernández Cortizo, "Estructura y composición del grupo doméstico en un medio urbano: Pontevedra a mediados del siglo XVIII", en Jubilatio. Homenaje de la Facultade de Geografia e Historia a los profesores D. Manuel Lucas Álvarez y don Ángel Rodríguez, Univ. de Santiago, 1987, I, y Arch. Histórico Provincial de Pontevedra, Catastro de Ensenada.
}

"CUADERNOS DE ESTUDIOS GALLEGOS", Tomo XLI, Fascículo 106, Santiago 1993-94. 
se recaudan sobre el vino, carne, aceite y sobre las ventas de textiles y las que se efectúan en el mercado semanal, esto es, básicamente sobre el consumo por menor. Añadamos aún que si en 1584 la villa estaba encabezada en 2.215.000 mrs. y Compostela en 1.500.000, dos siglos después las cantidades respectivas eran de 1.554 .322 y 10.600 .000 mrs., lo que demuestra de una manera rotunda la evolución contrastada, desde fines del XVI, de uno y otro núcleo.

A mediados del XVIII las gentes dedicadas al comercio representaban, aproximadamente, del 4 al 6 por cien del vecindario de las poblaciones urbanas; sólo en Coruña llegaban al 10 por cien. Pero estos porcentajes los obtenemos computando también a merceros, tenderos y taberneros, que forman la mayor parte de quienes viven de comprar y vender, aunque no deban propiamente incluirse en el grupo de la "burguesía mercantil" y, por ello, nosotros no les prestaremos gran atención en el curso de estas páginas. Conocemos bien, gracias a un trabajo del prof. Eiras Roel, cuál era la situación del mundo del comercio en la ciudad de Santiago ${ }^{6}$ : en el Catastro se censan 280 cambistas, mercaderes, merceros, tenderos y taberneros, pero sólo 60 de ellos declaran utilidades por encima de los 5.000 reales, y si el listón se sitúa en 10.000 los componentes de la burguesía mercantil quedarían reducidos a 27, bien pocos frente a 112 merceros, 63 tratantes de vino y 46 "tenderos de grosura". En muchos aspectos ocurre algo parecido en Coruña: el personal de legos registra tres "negociantes por mayor", 12 mercaderes, 84 merceros, tenderos y "medieros de Castilla", 39 taberneros (además de los que, como ocupación secundaria, venden algo de vino) y 74 tratantes de pescado y revendedores de fruta. ${ }^{7}$ Si bien en números absolutos hay menos gentes dedicadas al comercio en Coruña, la burguesía de esta ciudad declara unas utilidades medias superiores a la compostelana y tiene un mayor peso específico dentro de la economía urbana, según se desprende ya de su misma importancia demográfica. Las ganancias de los 12 mercaderes alcanzan de promedio los 17.383 reales (con el máximo en 32.000 y mínimo en 3.000); las de los merceros, tende-

\footnotetext{
${ }^{6}$ A. Eiras Roel, "La burguesía mercantil compostelana a mediados del siglo XVIII: mentalidad tradicional e inmovilismo económico", en A. Eiras Roel et alii, La Historia Social de Galicia en sus fuentes de protocolos, Univ. de Santiago, 1981.

${ }^{7}$ Arch. del Reino de Galicia, catastro de Ensenada, cuyo personal de legos consultamos detalladamente. Las respuestas generales han sido publicadas en la colección "Alcabala del viento", con introducción de B. Barreiro.
}

"CUADERNOS DE ESTUDIOS GALLEGOS", Tomo XLI, Fascículo 106, Santiago 1993-94. 
ros y "medieros de Castilla" se sitúan en 3.268,5 reales, las de los taberneros en 2.533 y las de los tratantes de pescado y revendedores de fruta en 1.103. En cualquier caso, también en la ciudad "llave del Reino" el comercio por menor, de tienda, taberna o plaza, era en 1750 el más importante así por las personas que ocupaba como por las utilidades totales que reportaba.

Un rápido repaso a lo que sucede en otras poblaciones urbanas nos permite afirmarnos, sin ninguna clase de dudas, en la escasísima capacidad económica de la burguesía mercantil gallega en el ecuador del siglo XVIII. En Pontevedra, por ejemplo, estaban avecindados nueve "mercaderes asturianos y otros por mayor", cuyas utilidades medias eran de 6.278 reales (el más rico, don Pedro de la Riega, ganaba 11.000 reales). Había además siete cambistas, uno de ellos ya retirado; cuatro que obtenían unos ingresos de 2.000 a 3.000 reales, y otro - don Jacobo Llorente-que alcanzaba los 20.000. En Betanzos, los cinco "negociantes por mayor" no sobrepasaban los 10.605 reales de utilidades medias cada año, y en Lugo el comerciante de mayor giro declara 4.800 reales de ingresos; tampoco en Ribadeo aparece ningún mercader o tratante cuya ocupación le reporte al menos 5.000 reales, y en Mondoñedo, en donde se censan 24 mercaderes y tenderos, el asturiano don Francisco Fernández Cueto gana 14.000 reales y los otros, todos menos de 5.000. En Tui dos comerciantes alcanzan los 20.000 reales de utilidades anuales, otro ronda los 5.000 mientras el resto de los vecinos vinculados a la mercaduría forma ya "un grupo variopinto y de raquíticos ingresos". Finalmente, Baiona, que en el siglo XVI compartiera con Coruña el privilegio de ser "llave del Reino" y de poder recibir navíos extranjeros, sólo contaba en 1752 con tres mercaderes, cuyos menguados ingresos oscilaban de 1.000 a 1.500 reales... ${ }^{8}$

A la vista de los datos expuestos es ocioso insistir en la debilidad que, como grupo socioeconómico, presenta la burguesía gallega del tiempo de la fuente ensenadina. En general, las grandes utilidades se obtienen con

\footnotetext{
${ }^{8}$ Hemos consultado los personajes de legos del catastro de Ensenada de Pontevedra, Lugo, Ribadeo y Mondoñedo (en los Archs. Histórico Provinciales de Pontevedra y Lugo); para Betanzos, B. Vaquero Lastres, "Un ejemplo de sociedad urbana en la Galicia del Antiguo Régimen: Betanzos en el siglo XVIII", pro. ms., Univ. de Santiago, 1986; para Tui, O. Rey Castelao, en la introducción a las respuestas generales de esta ciudad, aparecidas en la colección "Alcabala de viento"; para Baiona, M. García y García "Bayona en el siglo XVIII: economía y sociedad", pro. ms. Univ. de Santiago, 1991.
}

"CUADERNOS DE ESTUDIOS GALLEGOS", Tomo XLI, Fascículo 106, Santiago 1993-94. 
preferencia a través del arriendo de rentas reales o en otras actividades "especulativas" antes que en el tráfico de mercancías. Así, ningún comerciante de Pontevedra, Betanzos o Ribadeo declara ingresos comparables a los que reporta la administración y arriendo de salinas (el administrador de los alfolíes de Pontevedra gana 22.000 reales al año, y un receptor, a razón del 6 por cien de lo que vende, 18.000 , en tanto el mercader don Pedro de la Riega no pasa de 11.000). En ciertos casos, incluso el negocio del cambio parece más lucrativo que el del trato, pues el ya mencionado don Jacobo Llorente declara unas utilidades de 20.000 reales como cambista por mayor: "maneja, según se dice de público, un millón de reales de vellón suios propios, y los tiene puestos en la corte para negociar en girar letras o en los cambios que salen, y creen que negociándolos todos y empleándolos le dejarán un dos por ciento en el discurso del año", afirman los vecinos comisionados de la villa en las respuestas generales. Sabemos además, por un trabajo citado de A. Eiras, que el arriendo de salinas le proporcionó a Llorente unos beneficios del 28,2 por cien en 1728-36 y del 21,5 por cien en 1736-41, mientras que una compañía comercial que formó con otro socio en 1754-55 se saldó con unas ganancias del 6,7 por cien'.

Incluso en la ciudad de Coruña, en donde las gentes vinculadas al comercio tenían una mayor peso relativo, sus utilidades eran, desde todos los puntos de vista, bien cortas frente a lo que montaban los salarios del personal dependiente de la administración de justicia, militar y de la hacienda real. Los vecinos ocupados en el servicio real representan el 20 por cien de la población total y tienen unos ingresos globales que sobrepasan ligeramente el millón y medio de reales, 2,25 veces más que la suma de las utilidades de comerciantes, merceros, tenderos, revendedores y taberneros. El Capitán General, con un sueldo de 120.000 reales; el Intendente, con 75.000; el Intendente de Marina, con 60.000, serían la envidia del comerciante más rico, que no sobrepasaba los 32.000 reales. El Regente, un contador del Ejército y un tesorero, con un salario de 30.000 relaes; los mismos oidores, con 15.000, y en ciertos casos los relatores y escribanos de asiento, con 10-11.000, aventajan a algunos mercaderes, a los tres "negociantes por mayor" y no digamos ya a los merceros, tenderos y taberneros, cuyas utilidades medias no llegan, según vimos, a los 4.000 rea-

${ }^{9}$ A. Eiras Roel, "La burguesía mercantil...", art. cit., p. 549.

"CUADERNOS DE ESTUdIOS GALLEGOS", Tomo XLI, Fascículo 106, Santiago 1993-94. 
les, bien que se ha de tener en cuenta en esta y otras comparaciones que la fuente que venimos manejando es fidedigna en lo referido a los sueldos "oficiales", y no tanto en las cifras que ofrece sobre las ganancias que reporta el comercio y las "profesiones liberales". Un estudio de las estructuras familiares de la ciudad coruñesa - asunto que abordamos en otro lugar ${ }^{10}$ - nos revelaría que ciertos signos externos de riqueza y respetabilidad social, en particular el número de criados, son mucho más abundantes entre la burocracia dependiente del servicio real que entre las gentes del comercio, lo cual no constituye entera novedad, pues en la ciudad de Santiago sólo 11 comerciantes formarían parte de la elite urbana, constituida por 155 "familias", entre las que se cuentan la totalidad de los canónigos ${ }^{11}$.

Quizá no esté de más, sin embargo, advertir que no existía en el XVIII, como tampoco en el XVI y XVII, una oposición excluyente entre hidalguía y comercio, ni siquiera podía haberla en las poblaciones próximas a Asturias, en las que la proporción de nobles se sitúaba por encima del 15 por cien del vecindario total. En Santiago eran hidalgos varios comerciantes de lienzos, en Ourense se les reconoce esa calidad a ocho de 36 mercaderes, lo mismo sucede en Pontevedra con varios asturianos, y en Ribadeo. En las parroquias rurales de la mariña cantábrica y del curso medio del Eo son hidalgos rentistas - alguno figura como mayor hacendado de la localidad - los principales mercaderes de lienzos (caso de los Labrada, Santomé y Díaz de la Vega en Valadouro, de los Aenlle y Rocha en las riberas del Eo...). Veremos también como los más eximios representantes de la "nueva burguesía" vieron reconocida su condición hidalga sin grandes dificultades.

A modo de recapitulación podemos señalar que del análisis de los datos de las respuestas generales y libros personales del catastro de Ensenada se colige la existencia de una burguesía poco numerosa, débil económicamente y muy dependiente de las estructuras del Antiguo Régimen (a través del arriendo de rentas reales y de instituciones señoriales). Una burguesía, en palabras del prof. A. Eiras, "tradicional e inmovilista", "señorializada", "emisaria de economías externas" en cuanto que se dedi-

${ }^{10}$ Cfr. P. Saavedra, La Galicia del Antiguo Régimen. Economia y sociedad, Coruña, 1992, cap. V.

11 Vid. A. Eiras Roel, "Las élites urbanas de una ciudad tradicional: Santiago de Compostela a mediados del siglo XVIII", en Actas II Coloquio Metodología Histórica Aplicada. La Documentación Notarial y la Historia, Univ. de Santiago, 1984, I.

"CUADERNOS DE ESTUDIOS GALLEGOS", Tomo XLI, Fascículo 106, Santiago 1993-94. 
ca sobre todo a la importación (de textiles castellanos y del norte de Europa, de hierro, de algunos productos coloniales), mientras los únicos productos gallegos que exporta la burguesía son los lienzos ${ }^{12}$. Realmente no existe a la sazón, en una sociedad dominada por la renta feudal, una burguesía comercial que forme un grupo de contornos bien definidos e independiente. El contraste que los "Mapas Generales" del Catastro permiten efectuar mediante la comparación del valor de foros y diezmos, de una parte, y, de otra, del monto de las utilidades totales declaradas por mercaderes, tenderos y taberneros, es una prueba contundente de lo que venimos diciendo, y puede servir de conclusión al primer problema que consideramos oportuno abordar en este trabajo.

Utilidades totales del comercio por mayor y por menor y valor de foros y diezmos en $\mathbf{1 7 5 2}$, por provincias. En reales.

\begin{tabular}{lrrrrrrrr}
\hline Provincia & \multicolumn{1}{c}{ A } & \multicolumn{1}{c}{ B } & \multicolumn{1}{c}{ C } & \multicolumn{1}{c}{ D } & TOTAL & Foros & Diezmos & $\begin{array}{r}\text { Total foros } \\
\text { y diezmos }\end{array}$ \\
\hline Betanzos & 54.865 & 129.515 & 16.022 & 22.391 & 222.391 & 819.638 & 595.108 & 1.414 .746 \\
Coruña & 265.900 & 273.082 & 217.420 & 116.937 & 873.339 & 434.981 & 336.847 & 771.828 \\
Lugo & 28.920 & 68.292 & 28.898 & 13.950 & 136.700 & 2.972 .272 & 1.299 .763 & 4.272 .035 \\
Mondoñedo & 28.920 & 60.774 & 10.580 & 13.792 & 114.066 & 327.410 & 555.580 & 882.990 \\
Ourense & 247.026 & 70.660 & 64.344 & 11.992 & 394.022 & 3.009 .645 & 2.407 .706 & 5.417 .351 \\
Santiago & 584.512 & 221.871 & 145.390 & 21.602 & $973.375^{*}$ & 3.833 .705 & 2.652 .056 & 6.485 .761 \\
Tui & 107.860 & 46.068 & 28.226 & 20.600 & 202.754 & 698.575 & 1.091 .196 & 1.789 .771 \\
& & & & & & & & \\
TOTAL & 1.314 .643 & 870.262 & 510.880 & 221.264 & $2.917 .049 *$ & 12.096 .226 & 8.938 .256 & 21.034 .482 \\
\hline
\end{tabular}

$(*)$ Deben añadirse 19.575 rs. de utilidades de impresores y mercaderes de libros.

Leyenda: $A=$ utilidades de mercaderes por mayor y cambistas; $B=i d$., de mercaderes por menor, tenderos $y$ merceros; $\mathrm{C}=\mathrm{id}$., de tratantes por mayor $\mathrm{y}$ revendedores; $\mathrm{D}=\mathrm{id}$., de abastecedores de carne, vino y de taberneros. Fuente: AHN, Hacienda, "Mapas Generales del Catastro", legs. 7.440 y 7.441.

La hegemonía del "excedente feudal" resulta patente, toda vez que el valor de los foros cuadruplica con largueza las utilidades del comercio por mayor y por menor, y los diezmos las triplican, en tanto las rentas provinciales, no incluidas en el cuadro, las multiplicaban a la sazón por 2,75 . No es por tanto extraño que cualquier mercader que dispusiese de oportunidades invirtiese en compras de tierras o de rentas, en aparcería de gana-

\footnotetext{
${ }^{12}$ A. Eiras Roel, "La burguesía mercantil...", art. cit., pp. 558 ss.
} 
dos, o se dedicase al arriendo de rentas reales y señoriales. Semejantes opciones no reflejan sin más una mentalidad tradicional, sino que responden a condiciones objetivas y algunos de los comerciantes más poderosos de finales del XVIII - como Ibáñez y De la Riva-participaron en ellas. Lo que hay que averiguar precisamente es el destino que la burguesía comercial dio a las ganancias obtenidas en la gestión de la renta feudal. Repárese, finalmente, que en la provincia coruñesa, buena parte de las utilidades mercantiles procedían en 1752 del comercio por menor (apartados B, C y D), consagrado al abasto de la numerosa burocracia judicial y militar y de los innumerables litigantes que llevaban sus asuntos a la "fuente limpia", nombre con el que popularmente se conocía — aún doblado el siglo XX - el tribunal de la Audiencia.

\section{II.- EL AUMENTO DE LOS INTERCAMBIOS Y LA APARI- CIÓN DE UNA NUEVA BURGUESÍA}

En el curso del siglo XVIII tuvo lugar una notable expansión de la actividad comercial, según han puesto de relieve los estudiosos de las economías de las poblaciones urbanas del litoral, desde Ribadeo a Vigo ${ }^{13}$. Sin embargo, con independencia de los efectos que pudo tener la habilitación de algunos puertos - primero Coruña y después Vigo y Ferrolpara participar en el mercado colonial, se registraron con anterioridad cambios en el propio funcionamiento de la economía campesina, que significaron un importante retroceso del autoconsumo. No es fácil desentrañar las causas profundas de estos hechos, aunque su constatación no ofrece mayores dificultades.

Lo primero que llama la atención es el espectacular aumento del número de ferias y mercados. Por diversos informes de fines del XVIII sabemos que a la sazón se celebraban en Galicia más de 5.500 reuniones mercantiles al año, en su mayoría de carácter mensual. Para no alargar el texto ofrecemos a continuación un cuadro con el número de mercados semanales, ferias mensuales y anuales que existían en cada provincia en la década de 1790:

\footnotetext{
${ }^{13}$ Cfr., en especial, A. Meijide Pardo, La economía marítima..., op. cit., y Vigo..., op.cit.
}

"CUADERNOS DE ESTUDIOS GALLEGOS", Tomo XLI, Fascículo 106, Santiago 1993-94. 
Mercados semanales, ferias mensuales y anuales en las siete provincias de Galicia, ca. 1790

\begin{tabular}{lrrrc}
\hline Provincia & Mercados semanales & Ferias mensuales & Id. anuales & Total reuniones año \\
\hline Betanzos & 1 & 29 & 14 & ca. 442 \\
Coruña & 2 & 9 & 4 & ca. 224 \\
Lugo & 8 & 46 & 7 & ca. 989 \\
Mondoñedo & 3 & 13 & 20 & ca. 372 \\
Ourense & 1 & 37 & 7 & ca. 517 \\
Santiago & 16 & 87 & 21 & ca. 1.939 \\
Tui & 12 & 43 & 8 & ca. 1.164 \\
& & & & \\
TOTAL & 43 & 264 & 81 & ca. 5.647 \\
Reuniones/año & 2.236 & 3.168 & ca. 243 & ca. 5.647
\end{tabular}

Cada reunión equivale a un día de feria y mercado, y se calcula que de promedio las ferias anuales durarían tres días.

Fuente: AHN, Consejos, legs. 2919-2920, y Arch. Histórico Provincial de Lugo, Actas Municipales, a. 1798.

A fines del siglo XVIII había por tanto en Galicia un día de feria o mercado por cada 265 habitantes, aunque esta densidad variaba de una provincia a otra, como variaba también la importancia de las reuniones mercantiles: a algunas acudían gentes de varias leguas a la redonda y hasta comerciantes de fuera del Reino; otras duraban tan sólo unas horas, las suficientes para que los vecinos de una parroquia pudiesen vender o comprar unos ferrados de cereal, unas telas o media docena de cabezas de ganado menor. En el cuadro no es posible apreciar estos matices, cuya exposición ocuparía bastantes páginas.

Lo que ahora nos interesa señalar es que muchas ferias, en particular las de carácter mensual, habían ido surgiendo en el curso del XVIII, ya desde su primera mitad, tal como puede averiguarse a través de la obra de Larruga y de documentación diversa del AGS, AHN y Archivos Municipales. Los ejemplos con que contamos son muy numerosos. Por vía de muestra mencionaremos las ferias mensuales aparecidas entre 1720 y 1740 en Acibeiro, Cabarcos, Cervantes, cotos de Oca y Loimil, Galdo, San Martiño de Arroxo, Queizán de Carballo, Quireza, Rendar, Santiago de Nove, Sigüeiro, Souto Bermudo y Veiga de Forcas, localidades todas de carácter rural de las provincias de Lugo, Mondoñedo, Orense y Santiago. El movimiento se prolonga hasta avanzado el siglo XIX y en concreto en 
la provincia de Orense, entre 1807 y 1833 , una docena de poblaciones consiguen autorización para celebrar una feria mensual y otra un mercado semanal. También en el partido de Santiago diversas localidades dicen tener, en 1813, necesidad de una feria o, en menos ocasiones, de un mercado (casos de Ames, Bembibre, Brandomil, Bugallido, Bastavales, Buxán, Cacheiras, etc., etc. $)^{14}$. Determinadas ferias de gran antigüedad registraron ya con anterioridad a 1750 un notable florecimiento y están en el origen de ciertas villas actuales cabeza de municipio, como Carballiño, Monte-rroso, A Estrada, Ferreira de Valadouro, A Fonsagrada...

Según el censo de Floridablanca sólo 23 localidades superaban los 1.000 habitantes en la Galicia de fines del XVIII ${ }^{15}$; ahora bien, había unas 40 poblaciones con un mercado semanal y más de 250 con una feria de carácter mensual, lo que significa que buena parte de las reuniones mercantiles se celebraban en el mundo rural, debido a que el aumento de los intercambios, como anunciábamos más atrás, hunde sus raíces en los mecanismos de funcionamiento de la economía campesina antes que en hechos más espectaculares, por ejemplo la habilitación de puertos para el tráfico indiano. Muchas de las nuevas ferias que fueron apareciendo antes de 1790 surgieron por simple iniciativa de los vecinos, sin ningún tipo de privilegio o autorización: como dirían los dependientes de la Hacienda real, fueran "establecidas por el abuso y autorizadas por la costumbre". En $1790 \mathrm{el}$ Intendente Bañuelos señalaba que "el punto de las ferias de Galicia es un laberinto de difícil comprensión (...). Pasan de cuatro mil las que anualmente se celebran (...). La más pequeña parte de este cúmulo vicioso es lexítima (...). Pero el mayor perjuicio está en la actualidad en que se juntan seis, ocho o más personas y se convienen y determinan en que tal día y en tal paraje haya una feria con el sobre escripto de Franca, y fijan sus carteles de avisos al público en las iglesias parroquiales de la jurisdicción, y sin otra formalidad concurren gentes, quedando establecida"16. No se nos oculta que las ferias tenían un contenido que iba más allá de lo puramente económico: eran "recreaciones", nuevas formas de sociabilidad de

${ }^{14}$ Vid. O. Gallego Domínguez, "Ferias y mercados en la provincia de Orense", Boletín Auriense, XVII (1987); A. Rodríguez González, "Ferias en el partido de Santiago de Compostela en 1813", Boletín de la Universidad Compostelana, 75-76 (1967). Con carácter general, el tomo 43 de las Memorias de J. Larruga, pp. 113 ss.

${ }^{15}$ A. Eiras Roel, "Una primera aproximación...", art. cit.

${ }^{16}$ Arch. Histórico Nacional, Consejos, legs. 2919-20.

"CUADERNOS DE ESTUdios GALLEGOS", Tomo XLI, Fascículo 106, Santiago 1993-94. 
carácter profano, que competían o suplantaban a las de tipo religioso, en ocasiones debido a que el rigor de la jerarquía eclesiástica, al prohibir las comidas copiosas con motivo de los santos patronos de las cofradías, había traído como consecuencia que la tibieza se generalizase, en perjuicio del antiguo y explicable fervor.

La localización y forma de aparición de las ferias constituyen pruebas de que responden a nuevas necesidades de las economías campesinas. Pero el retroceso del autoconsumo no tuvo lugar porque cada vez hubiese más excedentes agrarios comercializables o porque se produjese una especialización comarcal, sino por todo lo contrario: fue la progresiva insuficiencia de las pequeñas explotaciones la que obligó a sus posesores a un mas intenso contacto con el mercado, ya se trate del mercado de productos artesanales, agropecuarios o de mano de obra (caso de la emigración estacional) ${ }^{17}$.

A través de los "Papeles Cornide" de la Real Academia de la Historia conocemos cuales eran las principales importaciones y exportaciones de Galicia en la década de 1780. El "comercio pasivo" o importaciones se componían de los siguientes productos:

Principales importaciones de Galicia, en la década de $\mathbf{1 7 8 0}$

\begin{tabular}{|c|c|c|c|}
\hline Artículo & Valor en rs. & Artículo & Valor en rs. \\
\hline $\begin{array}{l}\text { Paños, bayetas, sargas } \\
\text { de Castilla y Rioja }\end{array}$ & 14.000 .000 & $\begin{array}{l}\text { Géneros extranjeros } \\
\text { (textiles de Francia...) }\end{array}$ & 2.000 .000 \\
\hline $\begin{array}{l}\text { Lino de Rusia, } \\
\text { Indianas, medias, }\end{array}$ & 6.000 .000 & $\begin{array}{l}\text { Cacao, azúcar, etc. } \\
\text { Madera de pino de }\end{array}$ & 1.600 .000 \\
\hline pañuelos & 4.000 .000 & Portugal y Holanda & 1.000 .000 \\
\hline Sedas, productos de & & Cáñamo & 600.000 \\
\hline Talavera & 3.000 .000 & & \\
\hline Otras sedas, etc. & 3.000 .000 & Hierro de Asturias y Vizcaya & 600.000 \\
\hline
\end{tabular}

Estas salidas de numerario - a las que habría que añadir las que efectuaban rentistas que vivían fuera del Reino, las correspondientes al pago de bulas, y otras - se contrarrestaban en parte mediante la exporta-

\footnotetext{
${ }^{17}$ Insistimos en esta cuestión en "La dinámica de la pequeña explotación campesina en la Galicia del Antiguo Régimen", comunicación al X Congreso Internacional de Historia Económica, Leuven, agosto de 1990.
} 
ción de ganado vacuno y caballar (unas 3.000 mulas vendidas en las ferias de Monterroso y Padrón supondrían 2.400 .000 rs.), a través de la venta de hierro labrado en las ferrerías del Caurel y vendido en Castilla y Portugal (12.000 quintales en total, en 1.320 .000 rs.); mediante la exportación de sardinas y lienzos (cuyo valor no se indica), y a través de la emigración estacional y de corta duración: los 30.000 temporeros que cada verano se desplazaban a Castilla proporcionaban unos retornos de 4.500 .000 rs., en tanto de Portugal llegaban al menos 2.800 .000 rs. al año.

Por tanto, el desarrollo de la industria textil de los lienzos, el aumento de las ventas de ganado vacuno - y a fines del Antiguo Régimen también del mular-y el crecimiento de las importaciones de paños y otros artículos - utensilios de labranza y de cocina, productos coloniales - son algunos de los factores explicativos que están detrás de la multiplicación de las reuniones mercantiles. Había ferias "monográficas" de ganado y lienzos, y cuando no, los textiles y el vacuno rara vez faltan entre los objetos de compraventa. La industria textil basada en el lino contaba en Galicia con una gran tradición, según se desprende de ordenanzas municipales del XVI (por ejemplo de las de Mondoñedo y Viveiro), y de otras pruebas documentales que nos hablan de la exportación de lienzos en el curso del XVII, con destino sobre todo a Castilla: al mercado de Mondoñedo acuden, ya en la década de 1630, comerciantes riojanos, castellanos y asturianos a comprar tejidos de lino. En la segunda mitad del XVII los Cinco Gremios mayores de Madrid tenían factores en diversas ciudades gallegas para abastecerse de lienzos, y este artículo era incluso objeto de regalo a quienes en la corte favorecían la buena marcha de los pleitos de las cabezas de provincia. Y, a la postre, si en el último cuarto del siglo XVII se crearon las mantelerías coruñesas —estudiadas hace ya tres décadas por el prof. Enciso Recio- fue porque en el Reino había condiciones para que esta manufactura pudiese desenvolverse, tal como reconocía en 1721 el Intendente Rodrigo Caballero: "En ninguna parte de España se pueden hacer ropas de lino y lanas con mayor conveniencia ni de mejor ley que en Galicia, y lo que conviene es afinarlas más para su transporte a Indias, pues tengo entendido que a poca diligencia se pueden hacer lencerías de igual finura, pero de mayor ley que las extranjeras"18.

${ }^{18}$ Cfr. L.M. Enciso Recio, Los establecimientos industriales españoles en el siglo XVIII. La mantelería de La Coruña, Madrid, 1963. También los trabajos citados en la nota 1, y P. Saavedra, Economía, Política y Sociedad en Galicia: la provincia de Mondoñedo, 1480-1830, Xunta de Galicia, 1985, cap. V.

"CUADERNOS DE ESTUDIOS GALLEGOS", Tomo XLI, Fascículo 106, Santiago 1993-94. 
Antes de que, desde mediados de la década de 1770, algunos puertos fuesen habilitados para traer directamente lino del Báltico, hubo sin duda una fuerte expansión de la producción y comercio de lienzos, como prueba la proliferación de telares "nuevos" dentro de las casas campesinas al filo de 1740 y el que se importe lino del reino de León o, doblado el XVIII, de los países del Norte de Europa, vía Bilbao. No es extraño, por tanto, que hacia 1750 los tratantes de lienzos constituyan una fracción relativamente importantes de la burguesía mercantil, a pesar de que la venta de los tejidos estaba muy fragmentada: segadores temporeros, arrieros maragatos y comerciantes más o menos profesionales - en ocasiones hidalgos rurales que trataban también en bueyes - remitían los lienzos hacia Castilla (las exportaciones a Indias, desde 1764, absorven una parte pequeña del volumen comercializado). En muchos casos, los comerciantes de lienzos de mayor giro actuaban como simples comisionados de mercaderes residentes en ciudades castellanas, en especial en Madrid. Algunos que operaban por cuenta propia hacían envíos cuantiosos, como prueba el inventario de don José de la Vega y Río (Valadouro), fallecido en 1775, antes del inicio de las importaciones directas de lino: entre sus acreedores, por una cantidad de 115.813 reales, aparecen once comerciantes de Valladolid y seis de Madrid ${ }^{19}$.

En la segunda mitad del XVIII aumentó el número y la potencia económica de los mercaderes de lienzos, pero ello no supuso que desapareciesen las otras formas, fragmentarias, de comercialización de una parte importante de la producción textil, pues los segadores y los arrieros maragatos continuaron llevando cargamentos al interior. El hecho de que los tejidos fuesen elaborados de una manera autónoma por los campesinos, en un sistema de Kaufsystem, y la existencia de una creciente emigración estacional posibilitaban estas variadas y elásticas formas de envío de los productos industriales a sus puntos de destino. Cuando a mediados de la década de 1770 fueron autorizadas importaciones directas, para superar el estrangulamiento que se iba agudizando entre la cantidad de lino cosechada y las disponibilidades de fuerza de trabajo para hilar y tejer, un reducido grupo de comerciantes mayoristas - primero dos o tres casas de Ribadeo y luego media docena de grandes mercaderes compostelanos- controla-

\footnotetext{
${ }^{19} \mathrm{Cfr}$. P. Saavedra, "Industria textil rural e cambios demográficos na Galicia cantábrica, 1750-1860", Grial, 102 (1989), p. 242.
}

"CUADERNOS DE ESTUDIOS GALLEGOS", Tomo XLI, Fascículo 106, Santiago 1993-94. 
ron los cargamentos. Esta especie de elite de la burguesía mercantil era de origen foráneo, pues a la sazón ya se habían avecindado en las principales ciudades y villas gallegas, aprovechando la expansión de los intercambios, diversas "familias" de procedencia variada, algunas de las cuales acumularon en poco tiempo grandes beneficios ${ }^{20}$.

En la ciudad de Coruña, la autorización de 1764 para enviar Correos a Indias propició la arribada de mercaderes no naturales de Galicia que se dedicarán al negocio por mayor, con lo que se superó la situación de 1750, cuando - recordemos - Coruña era, desde el punto de vista comercial, una localidad de tenderos, merceros y taberneros. De la biografía de algunos de los recién llegados se ocupó en su día A. Meijide Pardo, y en la reciente monografía de Luis Alonso puede verse una relación de las principales colonias, reconstruida a partir de los protocolos notariales. En el último cuarto de siglo los gallegos representan tan sólo el 18 por cien de los comerciantes que participan en el negocio indiano: su número se eleva a 23, prácticamente el mismo que de catalanes; los vascos son 31, los castellanos y riojanos 17, y los extranjeros 9. Entre los 15 más gruesos negociantes sólo aparece, ocupando en el ranking el puesto décimo, un gallego (Genaro Fontenla) ${ }^{21}$.

Pero en otras poblaciones urbanas - y dejando ahora de lado las villas pesqueras invadidas por catalanes- la inmigración de comerciantes no vino motivada, al menos directamente, por el comercio indiano, sino por cambios económicos más profundos, que afectaban a todo el Reino y a los que ya aludimos. Así, en la ciudad de Santiago, al filo de 1760 se asientan algunos de los que luego estarán entre los mercaderes de mayor giro de Galicia: los riojanos don José de Andrés García, don Antonio Moreno y don Silverio Moreno, Martínez de la Riva... Poco a poco la colonia se irá engrosando. Aparecen otros de Palencia, Zamora, Medina de Rioseco,... y también de Asturias (entre los que descolla don Ramón Pérez Santamarina). La renovación de la elite de la burguesía mercantil se inicia, por tanto, antes de 1764 y prosigue hasta fines de siglo. El Almanak Marcantil de 1799 y 1802 revela que tal renovación fue profunda en Santiago, pero aconteció también en Ribadeo (en donde la pesca apenas tenía importan-

\footnotetext{
${ }^{20}$ Vid. J. Carmona, El atraso industrial..., op.cit., pp. $108 \mathrm{ss.}$

${ }^{21}$ Cfr. L. Alonso Álvarez, Comercio colonial..., op.cit., p. 180, y más ampliamente pp. 173-181.
}

"CUADERNOS DE ESTUdios GALLEGOS", Tomo XLI, Fascículo 106, Santiago 1993-94. 
cia), Vigo, Lugo, Ourense, Mondoñedo ${ }^{22} \ldots$

La envergadura de las empresas mercantiles acometidas por esta "nueva burguesía" constituye una novedad por comparación a lo que pasaba antes de 1750/60, pero la llegada de oleadas sucesivas se vio facilitada porque ya existían viejos y fuertes vínculos económicos entre Galicia y las zonas de origen de los avecindados. Y, en último término, ya residían en la primera mitad del XVIII - y antes - mercaderes foráneos en las poblaciones urbanas de Galicia. En Ribadeo, Pontevedra, Ourense y Vigo es de procedencia asturiana una parte de la burguesía comercial que se censa en el catastro de Ensenada. Los protocolos de Santiago de 1715-40 nos muestran a las gentes del Principado formando compañías, asociadas en ocasiones a compostelanos. En Vigo, desde 1720 los asturianos tienen un papel fundamental en los préstamos a riesgo de mar y aparecen como propietarios de diversas artes de pesća, según ha puesto de relieve $\mathrm{X}$. Carmona $^{23}$. El comercio del vino, de madera y de sal había permitido que desde el XVI al menos se estableciesen fuertes lazos entre Ourense, Ribadavia, las poblaciones urbanas litorales de Galicia y Asturias. La coyuntura de la segunda mitad del XVIII animó a vecinos de Lastres, de Puerto de Vega, de Avilés..., a desplazarse al país limítrofe, unos para prosperar en él, otros simplemente para vender calderos y herramientas diversas en las innumerables ferias que se celebraban por doquier, en las que eran conocidos los "bancos de los asturianos".

Los castellanos, por su parte, vendieron paños en Galicia durante toda la Edad Moderna e incluso puede decirse que el mercado del Noroeste peninsular, que aumentó en número de posibles consumidores en el curso de los siglos XVII y XVIII, fue adquiriendo una importancia creciente para la industria textil de media y baja calidad de los pueblos de Castilla, que por eso resiste mejor la crisis que la pañería de lujo, de carácter urbano. En los protocolos de la villa de Benavente, Bartolomé Yun ha podido comprobar como van creciendo, en la centuria dieciochesca, las remesas de textiles enviadas a Galicia, transportadas - al igual que sucedía, a la inversa, con los lienzos - en parte por temporeros vuelven de la siega o de la vendimia, tal como refleja la estacionalidad de las contrataciones ${ }^{24}$.

${ }^{22}$ X.R. Barreiro, "La burguesía compostelana...", art. cit., e Historia contemporánea..., op. cit. El mismo autor continúa preparando una extensa monografía sobre esta "protoburguesía".

${ }^{23} \mathrm{~J}$. Carmona, "Igualdade e desigualdade nas pesquerías galegas do século XVIII", Grial, 102 (1989), pp. 221 ss.

${ }^{24}$ Cfr. B. Yun Casalilla, Sobre la transición al capitalismo en Castilla. Economía y sociedad en Tierra de Campos (1500-1830), Junta de Castilla y León, 1987, pp. 532 ss.

"CUADERNOS DE ESTUdios GALLEGOS", Tomo XLI, Fascículo 106, Santiago 1993-94. 
$\mathrm{Al}$ igual que en el caso de los asturianos, también los castellanos aparecen antes de 1750, en la documentación notarial de Compostela, formando diversas compañías de comercio, pero no es hasta doblado el siglo cuando se avecindan algunos que descollarán en el mundo de la mercaduría y que ya no limitarán a la tradicional importación de paños de sus lugares de origen y a la exportación de lienzos. Otros se redujeron a continuar visitando las ferias, en particular de la provincia de Orense, según señala Larruga, o como nos informan, con mayor precisión los libros de guías y tornaguías a que dio origen la puesta en administración de las rentas provinciales desde primero de año de 1786 en las cinco ciudades del interior $^{25}$.

Tampoco los procedentes de Cameros eran desconocidos en Galicia. En la segunda mitad del XVI los textiles fabricados en localidades de la Sierra de la Demanda (Fresneda, Anguiano, Matute...) eran vendidos, en parte, en las ferias de Medina, a comerciantes gallegos y asturianos (también a castellanos) que los llevaban luego al Noroeste. En una carta de Simón Ruíz, de mayo de 1575, se indica precisamente que, a causa del hambre que afectaba a Galicia y Asturias, no se vendía en Medina una vara de paño con destino a estas zonas, para desconsuelo de los fabricantes riojanos ${ }^{26}$. Al menos desde mediados del XVII residen en poblaciones urbanas como Santiago y Coruña hombres nacidos en el obispado de Calahorra, y que se dedican a veces al arriendo o administración de las rentas provinciales. Sabemos también que algunos canónigos de Compostela tenían antepasados riojanos: un don Martín Moreno, cuyo expediente de limpieza es de 1664, declara que sus abuelos paternos eran de Anguiano y Pedroso; de esta última villa era también el padre de don Andrés Herce Santos, bautizado en Coruña en 1647 y que en 1684 aspiraba a una canongía; en 1647 había nacido en Santiago don Miguel López Andiano, cuyo padre era asimismo de Pedroso y ocupaba en Coruña el cargo de tesorero de alcabalas y diputado de la Santa Cruzada; por fin, de

\footnotetext{
${ }^{25}$ Especialmente ricos en documentación de este tipo son los Archs. Históricos Provinciales de Lugo y Orense. Una valoración de los fondos de este último en O. Gallego Domínguez, "Hacienda y fiscalidad en la Galicia del siglo XVIII", en la obra colectiva Fuentes para el estudio del siglo XVIII en Galicia. Historia Económica y Social, CoruñaSada, 1991, pp. 47 ss.

26 Tomamos esta referencia de la tesis de Estado de F. Brumont, Paysans de Vielle Castille au XVI-XVIIème siècles, Toulouse, 1989, en curso de publicación por la Casa de Velázquez.
}

"CUADERNOS DE ESTUDIOS GALLEGOS", Tomo XLI, Fascículo 106, Santiago 1993-94. 
1709 data el expediente de don Baltasar Llorente de Castro, con antepasados en la vila de Matute. Los Llorente comenzaran estableciéndose en Pontevedra, para luego extender su comercio a Vigo y Santiago. Su integración en la vida local fue completa: matrimoniaron y desempeñaron cargos concejiles en las poblaciones citadas y don Jacobo Llorente de Araújo vio reconocida su calidad hidalga en Santiago en 1734, y en 1752 consiguió el título de Marqués de Astáriz ${ }^{27}$. Así que antes de 1760 estaban establecidas intensas relaciones comerciales - y humanas- entre Galicia y las localidades industriosas de la Sierra de la Demanda: hacia 1740 había en Soto de Cameros 48 comerciantes, además de "otras cuatro compañías que mantienen los vecinos de esta población con Galicia". Como bien ha señalado el prof. Agustín González Enciso, a la sazón, los paños de baja calidad fabricados en Soto, Ortigosa, Enciso y Torrecilla se vendían principalmente en Galicia ${ }^{28}$.

\section{III.- NUEVAS Y VIEJAS PRÁCTICAS BURGUESAS}

Hemos venido insistiendo en que la renovación de la burguesía mercantil gallega no se explica tan sólo por la habilitación de Coruña al tráfico indiano o por las oportunidades que ofrecía la actividad pesquera. Hubo ya antes de 1760 un aumento de los intercambios generado por la propia dinámica de la economía campesina y ello motivó una afluencia creciente de mercaderes foráneos, algunos de los cuales acumularon luego grandes beneficios en el tráfico colonial o en la importación de linos del Báltico. La ausencia de una burguesía autóctona bien definida no ha de atribuirse, de una manera simplista, a la "falta de espíritu empresarial": hasta avanzado el XVIII la economía gallega era esencialmente importadora (si bien la balanza se compensaba con una considerable exportación temporal de fuerza de trabajo) y los comerciantes que venían a vender los artículos, cuando doblado el siglo barruntaron cambios, decidieron quedarse, ocupando el vacío que existía no por razones de "mentalidad", sino debido a la situación objetiva en que se había venido desenvolviendo la economía del Rei-

${ }^{27}$ Sobre la geneología de los Llorente, P. Pérez Costanti, "Linajes galicianos", Boletín de la Real Academia Gallega, VI, pp. 250 ss.

${ }^{28}$ Cfr. A. González Enciso, "La protoindustrialización en Castilla la Vieja en el siglo XVIII", Revista de Historia Económica, 3 (1984), pp. 65 ss.

"CUADERNOS DE ESTUdIOS GALLEGOS", Tomo XLI, Fascículo 106, Santiago 1993-94. 
no. A fin de cuentas no ha de olvidarse que aunque minoritario, hay un grupo de "nuevos burgueses" gallegos en Coruña y otro en Santiago.

Los inventarios de mercaderes y contratos de disolución de compañías de fines del XVIII y comienzos del XIX ponen de relieve que determinadas familias y asociaciones manejaron un capital notable. Sin embargo apenas hay novedades en las formas de asociación mercantil: salvando las compañías de seguros marítimos que se crean en la década de 1780 y que están formadas por diversos accionistas, en el comercio predomina el negocio familiar, las compañías colectivas y, en el caso del tráfico colonial, las commendas. Varios riojanos comenzaron como mancebos de convecinos que habían salido ante de su tierra; con el tiempo, los mancebos podían llegar a socios y hasta a yernos de quien les enseñara el oficio ${ }^{29}$.

Muchas de las compañías comerciales escrituradas en la segunda mitad del XVIII se constituyen con pequeños capitales, a menudo inferiores a los 300.000 reales, si bien algunas de Santiago y Coruña superan los 700.000. Por lo que toca a la primera mitad de la centuria no encontramos, de momento, ninguna asociación que supere en el momento de constituirse los 400.000 reales: cinco compañías formadas en Compostela entre 1715 y 1750 , y en las que participan asturianos y castellanos, tienen unos fondos que oscilan de 26.000 a 397.000 reales, y proporcionan unos beneficios anuales que oscilan entre el 0,73 y el 35 por cien. En los contratos de disolución se percibe el peso que tienen las deudas a favor, derivadas de la práctica de venta a crédito o "al fidado": una compañía de cuatro socios, por ejemplo, liquidada en 1744 , presentaba un activo de 598.826 reales, de ellos 183.314 en mercancías existentes y 261.040 en deudas a favor ${ }^{30}$.

En el tránsito del XVIII al XIX hay inventarios y balances en principio espectaculares, pero el grueso del activo continúa formado por deudas a favor: la sociedad Vda. de Vieites y Compañía, de Santiago, presentaba en 1794 un activo de 812.956 reales, de los cuales 579.731 eran deudas a favor, 74.236 mercancías extranjeras y 95.294 mercancías nacionales. Hasta 1800 la compañía obtuvo unos beneficios de. 67,25 por cien. Más llama-

\footnotetext{
${ }^{29}$ X.R. Barreiro Fernández, "La burguesía compostelaia...", art. cit.

${ }^{30}$ Balances de estas y otras compañías parecidas en Arch. Histórico Universitario de Santiago, Protocolos, legs. 3539, 3546, 3860, 3865, 3872 y 3879, y en R. Loureiro Picos, "Las compañías de comercio en Santiago en el siglo XVIII", pro. ms. Univ. de Santiago, 1989.
}

"CUADERNOS DE ESTUDIOS GALLEGOS", Tomo XLI, Fascículo 106, Santiago 1993-94. 
tivos son los balances de las diversas compañías formadas por don José de Andrés García: en febrero de 1799 el activo de las casas de Santiago, Padrón y Carril montaba la cantidad de 9.514.021 reales, pero 8.049.799 eran deudas a favor, en tanto los géneros ascendían a 1.102.840 reales y los bienes raíces a 99.816,5. En el voluminoso inventario de 1804 la casa de Santiago tenía un activo de 11.341.603 reales, ascendiendo las deudas a favor a 8.720 .845 , los géneros a 974.632 y los raíces a 311.258 ; la casa de Carril figura en el mismo inventario con un saldo a favor de 2.619 .513 reales, entre los que se contaban 1.770 .978 de deudas activas y 803.272 en géneros. Básicamente las mercancías consisten en textiles de media y baja calidad de Castilla y la Rioja, amén de algunos paños de Francia e Inglaterra, hierro, papel y productos coloniales. También consta la importación de vinos franceses. En la casa de Santiago eran importantísimas las deudas por lino -a ello aludiremos luego- introducido sobre todo por Ribadeo. Las seis compañías en que participó don José de Andrés García, o sus herederos, entre 1781 y 1812 (puede haber otras de las que no tenemos datos) se liquidaron con beneficios que oscilaron entre el 10,5 y el 49,8 por cien. Nótese, finalmente, como en el inventario de 1804 los bienes raíces - al igual que sucede en el caso de la burguesía gaditana o valenciana- tienen, porcentualmente, escasa importancia. Lo mismo se comprueba en el inventario de don Ramón Pérez Santamarina, de 1808, que conocemos gracias a las investigaciones de X.R. Barreiro Fernández: de un activo líquido de 11.577 .465 reales, 686.337 corresponden a la tasación de raíces y rentas ${ }^{31}$.

Los miembros más destacados de la nueva burguesía no sólo acometieron, en el comercio colonial o importando linos, empresas que requerían grandes desembolsos. Mostraron también una cierta iniciativa industrial: pequeñas fábricas de productos textiles fueron montadas en Coruña, Vigo y Santiago. Las fábricas de curtidos de los arrabales de Santiago y Carril fueron levantadas por Pérez Santamarina, Cabello Mayoral, de Andrés García... Este último participó también en la fundación de Sargadelos - tal como ha probado documentalmente A. Meijide Pardo-, aunque después se retiró de la empresa. Los castellanos, riojanos y hasta los galle-

${ }^{31}$ Cfr. X.R. Barreiro, "La burguesía compostelana...", art. cit., e Historia contemporánea..., op. cit., pp. 382 ss. El extenso inventario de la compañía de Andrés García, que consultamos personalmente, en Arch. Histórico y Universitario de Santiago, Protocolos, leg. 7438 .

"CUADERNOS DE ESTUDIOS GALLEGOS", Tomo XLI, Fascículo 106, Santiago 1993-94. 
gos adquirieron fábricas de sardinas, que, contra lo que a veces se cree, no fueron monopolio de los catalanes (ni éstos innovaron tanto, en lo que toca a la organización del trabajo, como con frecuencia se ha escrito). Otras inversiones menos espectaculares nos parecen sin embargo significativas: una de ellas sería la erección de una ferrería en los Ancares, en la década de 1790, financiada por un grupo de comerciantes de esta comarca (de la aldea de Pereda), enriquecidos en el tráfico con Ferrol ${ }^{32}$.

Pese a algunas actitudes nuevas hay que decir que la burguesía de fines del XVIII es fundamentalmente importadora y reexportadora, y que sus bases comerciales son precarias: la mayoría de los barcos que poseen Marcó del Pont, de Andrés García y otros proceden de presas de la práctica del corso, cobradas directamente o compradas. Durante las guerras finiseculares no hay comerciante de relieve que no arme buques corsarios ${ }^{33}$. La importancia de cargamentos de lino parece haber proporcionado a un reducido grupo de mayoristas sustanciales beneficios, pero la fabricación de lienzos no notó, en cuanto a su organización, transformación alguna: los propietarios de los cargamentos se limitaron a vender la materia prima directamente a los campesinos - a menudo al fiado - o a comerciantes intermediarios, que acaparaban grandes cantidades. No se estableció ningún tipo de domestic-system. Este "conservadurismo" de la más boyante burguesía mercantil, y que a la postre contribuyó al fracaso de la industria rural doméstica, puede parecer sorprendente, cuando al mismo tiempo alguno de sus más destacados representantes invertía en la siderurgia o en los curtidos. Para explicar esta aparente paradoja J. Carmona ha señalado que, dadas las características que tenía la fabricación de lienzos —obra de pequeños campesinos, que blanqueaban en hilo, lo que daba como resultado unos tejidos irregulares y de baja calidad-, la última fase de la producción era difícil de "tomar" por el capital comercial, que no intervino para nada en el proceso productivo ${ }^{34}$. Ni los mayoristas importadores y ni los intermediarios hicieron por lo general otra cosa que vender el lino al

${ }^{32}$ X.R. Barreiro Fernández, Historia contemporánea..., op. cit., p. 378 ss. A Meijide Pardo, Documentos para la historia de las Reales Fábricas de Sargadelos, A CoruñaSada, 1979 y Vigo..., op. cit. J. Carmona ha revisado el papel de los catalanes en actividad pesquera en su la segunda parte de sus tesis (lamentablemente inédita), "Producción textil rural e actividades marítimo-pesqueiras na Galiza, 1750-1905", Univ. de Santiago, 1983.

${ }^{33}$ A. Meijide, Vigo..., op. cit., y L. Alonso Álvarez, Comercio colonial..., op. cit., pp. 219 ss.

${ }^{34} \mathrm{~J}$. Carmona, El atraso industrial..., op. cit., pp. 171 ss.

"CUADERNOS DE ESTUDIOS GALLEGOS", Tomo XLI, Fascículo 106, Santiago 1993-94. 
fiado, como prueban los inventarios y demandas por deudas. En el recuento ya mencionado de Andrés García y Compañía, de 1804, se relacionan bajo el epígrafe "linos de Ribadeo" 48 personas, que deben en total 1.591.127 reales (el intermediario don Manuel Fernández Quintana debe $307.144,5$ reales y don José Antonio Campoamor, 172.705). Bajo el rótulo "linos de Vivero" figuran tres comerciantes adeudando 105.928 reales. A su vez, en el "libro de caja" se relacionan 133 personas de la Galicia cantábrica y de la parte occidental de Asturias cuyas deudas ascienden a 3.648.993,5 reales; algunas de ellas son intermediarios, a juzgar por las cantidades que no han pagado: 403.002 reales debe don Pablo Suárez Villamil, de Ribadeo; 240.945, don Sebastián Piñeiro, de la misma vecindad; 192.752, don Antonio López Villapol, de Viveiro..., y podrían citarse otros ejemplos. Pero todos deben en general lino que sacaron a crédito, sin que nada haga suponer un domestic-system. Tampoco los intermediarios ni los comerciantes de lienzos se decidieron por esta práctica: el inventario de don José Campoamor, ribadense, del mismo año que el de Andrés García, enumera 598 deudores por la cuantía de 588.015 reales, sin que ninguno de ellos tenga obligación de devolver tejidos elaborados con el lino adquirido. Lo que deben es el precio del lino fiado ${ }^{35}$.

El hecho de que la "nueva burguesía" dé muestras de un comportamiento "bifronte", participando de un lado en iniciativas industriales y adoptando de otro una actitud más tradicional —en su relación con la actividad textil o con las instituciones rentistas-, ha de explicarse a partir de las condiciones socioeconómicas vigentes en el Reino, y en particular de la hegemonía aplastante de la renta "feudal" y de los rentistas. El aumento del número de comerciantes y del volumen de los negocios no parece haber modificado el "tono" o ritmo de vida de la mayoría de las poblaciones urbanas, y sobre todo de las ciudades episcopales. El tosco "diario" del tejedor tudense Pedro dos Santos, centrado en los años finales del XVIII y comienzos del XIX, es al respecto muy indicativo. Los acontecimientos de los que toma nota se refieren a adornos de iglesias (colocación de lámparas, de campanas...), misiones anuales predicadas por miembros de las órdenes mendicantes, muerte del obispo y entrada del sucesor, jóvenes que profesan de monjas... Tales eran los sucesos que a fines del

${ }^{35}$ Arch. Histórico y Universitario de Santiago, Protocolos, leg. 7438, para el caso de Andrés García, y Arch. de Protocolos de Ribadeo, T. Pillado, 1804, para el de José Campoamor.

"CUADERNOS DE ESTUDIOS GALLEGOS", Tomo XLI, Fascículo 106, Santiago 1993-94. 
Antiguo Régimen se consideraban importantes en Tui ${ }^{36}$.

Las inversiones que la burguesía mercantil efectúa en bienes raíces y rentas tampoco han de atribuirse, sin más, a una mentalidad tradicional. No son específicas de una época y pueden documentarse desde el momento que se conservan protocolos (fines del XV en algunas poblaciones urbanas, como Pontevedra). En el ramo concreto del lino, el propio sistema de venta al fiado conllevaba el que las tierras de los campesinos insolventes acabasen en manos de los comerciantes importadores o redistribuidores. Tal es la razón por la que vemos desfilar por el Registro de Hipotecas de Mondoñedo a la más pujante burguesía de Ribadeo, desde la familia Villaamil hasta Ibáñez. Este, por ejemplo, reclamaba en 1798 una cuantiosa deuda por lino al mercader intermediario don Francisco Javier Montouto, quien manifestaba que no había podido satisfacerla por la insolvencia de campesinos a los que vendiera la mercancía, "y otros, por no tener dinero con que satisfacerlo, otorgaron a favor del dice escrituras de venta de bienes raíces", escrituras que entrega al administrador de Ibáñez, junto con diversos memoriales de deudas ${ }^{37}$.

Los burgueses asentados en las villas y ciudades participaron a veces activamente en la vida local, aprovechando el ejercicio del cargo de procurador general y los nuevamente creados a partir de las reformas administrativas motivadas por los alborotos de 1766 . El desempeño de tales cargos puede verse como un medio utilizado por la burguesía comercial para incorporarse a la elite local, pero también es cierto que la actividad de los ayuntamientos se vio en ocasiones dinamizada por el esfuerzo de personas deseosas de lograr privilegios mercantiles para las poblaciones de las que eran vecinos: Ibáñez en Ribadeo y Marcó del Pont en Vigo son buenos ejemplos de lo que decimos.

Finalmente, tampoco habrá de verse sin más como síntoma de una mentalidad tradicional el que muchos de los nuevos burgueses traten de ennoblecerse, cosa que también hicieron poderosas familias de la burguesía industrial catalana, sin por ello renunciar a sus negocios ${ }^{38}$. En Santia-

${ }^{36}$ El "diario" de Pedro dos Santos fue publicado por J.M. Álvarez Blázquez con el título de "Memorias de un menestral curioso", en Museo de Pontevedra, XIII (1958).

${ }^{37}$ Arch. de Protocolos de Ribadeo, Pérez Gayol, 1789. Las Hipotecas de Mondoñedo en Arch. Histórico Provincial de Lugo; consultamos los años 1768-1800 para la elaboración del libro Economía, Política..., Op. cit., caps. V y IX.

${ }^{38}$ El prof. P. Molas ha dedicado numerosos trabajos a las actitudes económicas y sociales de la burguesía; a modo de síntesis, vid., La burguesía mercantil en la España del Antiguo Régimen, madrid, 1985, pp. 156 ss. y 226 ss. Sobre una importante familia burguesa, cfr. R. Fernández, "La burguesía barcelonesa en el siglo XVIII: la familia Gloria", en P. Tedde (edr.), La economía española al final del Antiguo Régimen. II. Manufacturas, Madrid, 1982, pp. 98 ss. 
go, don José de Andrés García vió reconocida en 1783 la condición de hidalgo y continuó formando compañías el resto de su vida, hasta principios del XIX ${ }^{39}$. Mientras estuvieron en vigor los privilegios estamentales era casi inevitable que cualquiera que aspirase a un reconocimiento social buscase una ejecutoria o un título de hidalguía. De comienzos del XIX contamos con varios casos en Santiago: don Anselmo Cabello Mayoral logra en 1807 real cédula al efecto; don José Cabezudo Pedrosa, de Baltanás, la consigue en 1811; don Francisco Antonio González de la Hera, natural de Ortigosa de Cameros, en $1816^{40} \ldots$ En general, quienes aspiran a que se les reconozca la calidad de nobles aducen que sus antepasados eran hidalgos, aunque las cédulas de concesión destaquen los beneficios que al Estado y a la comunidad les resaltan de su actividad económica. Don Anselmo Cabello Mayoral, por ejemplo, natural de Medina de Rioseco, alega que sus antepasados eran hidalgos, y algunos de ellos participaran en la batalla de Clavijo... La cédula que obtiene afecta admitir tal suposición - y contiene una disparatada hipótesis sobre el origen del apellido Cabello-, pero destaca también que el solicitante tiene otros méritos: "socio principal capitalista y jefe de la casa que girais bajo el nombre de D. Andrés García y Compañía, la cual es de cambio y lonja cerrada, con establecimientos radicados en Ribadeo, Vivero, Padrón, Carril y Buenos Aires; que habéis hecho dos fábricas de prensa y salazón de sardina de la costa de Galicia, con las redes y aparejos necesarios"; que es dueño de una fragata y dos bergantines ("detenidos, a causa de la guerra, el uno en Marsella y el otro en Muros"); "que hicisteis la parte más principal de las fábricas de fundición de Sargadelos por mitad con el comisario de la Marina graduado D. Raimundo Ibáñez, a quien cedió después la misma casa de comercio su parte por convenio particular"; que satisfizo en 1789-90 en la aduana coruñesa más de 500.000 rs. al real erario, sin contar lo pagado en otros puertos; "que por el concepto y estimación que os habéis granjeado en la referida ciudad de Santiago fuisteis aclamado Diputado del Común de ella y desempeñasteis este cargo con exactitud y reconocido acierto..."41.

${ }^{39}$ Arch. Municipal de Santiago, Consistorios, 1783, y P. Pérez Costanti, "Linajes...", art. cit., IV, 238

${ }^{40}$ Datos sobre ennoblecimientos se encuentran en el Arch. Municipal de Santiago, Consistorios y "Expedientes de hidalguía", y en P. Pérez Costanti, "Linajes...", art. cit.

${ }^{41}$ P. Pérez Costanti, "Linajes...", art. cit., V, pp. 8-9.

"CUADERNOS DE ESTUDIOS GALLEGOS", Tomo XLI, Fascículo 106, Santiago 1993-94. 
En alguna manera es explicable que algunos burgueses avecindados en Compostela afirmen tener antepasados que partiparan en la batalla de Clavijo. Con tales causantes, ¿cómo se les iba a negar la condición de hidalgos en la ciudad del Apóstol? ${ }^{42}$. Bien lo sabía don Silverio Moreno Ibáñez, cuando en 1807 afirmaba descender de "hijosdalgo notorios de sangre, como oriundos y originarios de la casa y antiguo solar de Tejada, que radica en la sierra de Cameros", para añadir que un antepasado suyo, el año (era) 872, "con el favor de Dios, venció a los moros el día 21 de mayo de dicho año, quedando apoderado de los fuertes de Viguera y Clavixo"; posteriormente un hijo de este guerrero y doce caballeros galicianos poblaran la montaña de Valdeosera... El escudo que don Silverio Moreno es autorizado lucir en su morada recuerda tan desmedidas azañas: "está cercado de una orla de oro con trece banderas azules sobre la orla y en cada bandera un hábito del Señor Santiago", y una leyenda de la "Epístola Canónica del mismo Santiago que dice: Ecce beatificamus eos qui substinuerunt"43.

${ }^{42}$ Sobre el tema jacobeo, vid. O. Rey Castelao, La historiografia del Voto de Santiago. Recopilación crítica de una polémica histórica, Univ. de Santiago, 1985.

${ }^{43}$ P. Pérez Costanti, "Linajes...", art. cit., VI, pp. 287-290.

"CUADERNOS DE ESTUDIOS GALLEGOS", Tomo XLI, Fascículo 106, Santiago 1993-94. 